\title{
AN INTRODUCTORY REVIEW ABOUT DEFENCE MANAGEMENT: A CONCEPTUAL FRAMEWORK
}

\author{
Dr. P. Balathandayutham ${ }^{1} \bowtie(0)$ and Dr. V. Muralidharan ${ }^{2}$ \\ ${ }^{1}$ Assistant Professor, Department of Business Administration, Government Arts and Science College, Valparai, India \\ ${ }^{2}$ Principal, Government Arts and Science College, Valparai, India
}
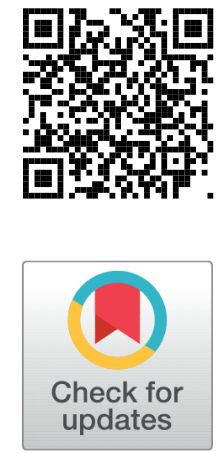

\section{ABSTRACT}

The concept of defence management refers to the process to plan, to organize, to staff, to direct and to control the activities in any organization for achieving the common goal in a very systematic manner. Further, the term management refers to both a method of science as well as art to empower individuals and to make an institution more efficient and effective when compared to the state without the manager and the management. As a process of the institution, the defence management lies amidst the policy formation for defence and the actual control and command of the forces in the military sector. defence management covers elements like management of the resources of defence sector, management of the personnel in the field and acquisition management.

Keywords: Defence Management, Management

Received 29 May 2021

Accepted 10 June 2021

Published 30 June 2021

DOI $10.29121 /$

granthaalayah.v9.i6.2021.3978

Funding: This research received no specific grant from any funding agency in the public, commercial, or not-for-profit sectors.

Copyright: (C) 2021 The Author(s). This is an open access article distributed under the terms of the Creative Commons Attribution License, which permits unrestricted use, distribution, and reproduction in any medium, provided the original author and source are credited.

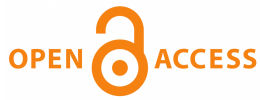

\section{DEFENCE MANAGEMENT- AN INTRODUCTION}

Nearly for more than fifty years, the concept of defence has been recognized as a public product that is developed by the government of a democratic nation for the security of the general public. At the same time, it was identified by the scientific world that, the government is not able to develop an efficient defence department, because of its inefficient nature. The interrogation was done during at that time by the governments on how to develop an efficient defence department. The answer to this query was identified as to implement the practices of management in the defence department. The term management refers to the science with the help of which the organizations of any nature, acts for meeting the objectives in any type of situations and in an efficient and effective manner. This is done by the effective performance in planning, in organizing, in leading and in controlling.

For considering the implementation of the approaches of management in defence and such other typical issues, the management practices should arise in general framework of the democratic concerns instatus of defence and also the enquiries 
related to the outputs defence department in general and the defence forces, in particular.The managerial practices are the pre-requisite for any form of organization, may it be defence or any other, and also involving public money, to implement their own measures for improving the efficiency.

\section{DEFENCE MANAGEMENT- DEFINITION}

Till date, there is no one concrete definition for the term defence management. To be simple, defence management summarizes the fact that the organizations performing defence activities have to implement the policies of defence into practice. This is has to be followed by them for developing a sustainable and al appropriate mechanisms of planning, infrastructure and support system.

From the management point of view, actual planning is a bit varied from the planning for the operations of military campaigns. But, the planning for military operations too has got an effect over the acquirement of major equipment for military operations or for the development of the defence force. The term managerial planning refers to paying attention to the final goals of the organization and also the flexibility with which such goals has to be accomplished. Further, from the management point of view, the term organizing means the providing flexibility to the hard and rigid structures through the organization of the process of work within the limits of the structures rather re-structuring the entire work process or the structure.

The term leading refers to both taking the responsibilities as well as delegation of elements of the process of decision-making, which is totally different in the command chain of the armed forces, that is well-established. The concept of controlling refers to the keeping track of the developments and obstacles, in order to make the employees focus on the achievement of the objectives. On the contrary, the concept of defence management cannot and does not substitute the planning and performance of the military operations. Defence management can bring together the individuals inside the defence departments along with the training being given for accomplishment of missions, with the required support and equipment for the achievement of the missions and goals of the defence organization.

\section{3. 'MANAGEMENT' AND 'DEFENCE MANAGEMENT'}

The concept of management had been utilized in a quite number of ways. It is referred to as the several decisions which are needed for operating the complicated production process or to run an organization which operates as a non-profit organization. defence management is a form of descriptive approach which is utilized for explaining the term management as a procedure as well as the works of supervisors and managers. On the other hand, the term management can be used by anybody for directing persons for achieving an aim through the usage of minimal resources and also in minimal possible time period. Management can also be used to describe 
the field of knowledge which had been accumulated on the basis of economic, political, anthropological, philosophical, sociological or psychological theory for creating a systematic theory of how to achieve the specific aims by way of activities that are scientifically determined, creation and usage of proper organizations and utilizing the limited resources.

The modern management focuses both on administration as well as business. This should be the point of reference when a person adapts the practices and principles for any type of public activity or private activity or even personal activity. Some of the well-known fathers of management include Chester Bernard, Henri Fayol and Max Weber who had focused on the entire organization. On the other hand, Henry Gantt, Lillian \& Frank Gilbreth Frederick W. Taylor had paid attention to the fact that management is needed for increasing the productivity of the organization.

The abovesaid management studies regarding the management of business comprised of research as well as applied work. These studies resulted in the formation of the theory of administration and the scientific management, which serves to be the basis for the theory of classical management. Theory of administration focused on the functions of management and tried to formulate broader principles of administration, which serve to be the guidelines for the rationalization and validation of the activities of the organization. The famous author Taylor $\&$ his followers had stated that the activities of the individual employees can be analyzed in a scientific manner, in order to explore the procedures which can maximize the output with the minimal utilization of resources as well as energy.

\section{CONCEPT OF DEFENCE MANAGEMENT}

A clear explanation regarding the idea of the management of the defence organization lies in the notion of the uniqueness of the defence of the country when compared with the other civic organizations of the country. The reply for this query can be identifies or explored from the varied ranges of theoretical practices and options amidst the answers of "completely civic", "varied in a few aspects" and "completely varied". If the query is made from the spectrum of democracy, the responses are made on the basis of the liberalism of the society.

The first option, that is, "completely different" state that the defence organizations are exceptional and totally different from civil service system of the nation, may it be legal status, human rights, rights of the citizen, regulations, process of allocation of the resources, accountability and transparency.

The second part, varied in few aspects only refers to the fact that a specific state and society have got a all-inclusive system of instruments for national security, which as a system are designed for meeting the security demands of the general public. Therefore, it would be exact to state that defence have to be made a difference amongst the other civic organizations in extraordinary issues and situations. 
In the third state, that is "completely civic", it is commonly observed amidst the liberal and mature democracies, in which a society that is better developed, has framed mechanisms and procedures for the entire subjective and objective control as well as responsibility of the organizations of the security sector.

Tansu Demir \& Ronal Nyhan had argued in their study that the difference amidst the administration and politics affects the public administration. This is because, several administrators continue to make the promotion of the ethics of neutral competence for protecting their independence from the interference of the political system. This idea is significant in the field of defence in which the disassociation of military from the politics becomes essential both for the organization as well as for the society.

The modern organizations for defence should be developed in such a way that it is capable of resolving the strenuous association between the 3 main areas of defence functions which include politics, command and administration. It is the need of the hour to have a concrete dissection of power and labor among the managers, commanders and politicians. This is needed for the maintenance of the institutional cohesion as well as for coordinating the varied processes of the organization. This procedure proves to be a challenging one and each nation implements this process on the basis of its traditions, bureaucratic culture and societal development.

\section{INTEGRATED CONTEXT OF DEFENCE MANAGEMENT}

To make the defence management as a rational tool for the defence organization, the development, reformation or the transformation starts with the recognition of the fact that all the persons included (managers, commanders and politicians) perform the activities in specific internal and external contexts. It becomes essential for the managers, commanders and politicians to recognize and understand the way in which the aforesaid contexts affect the development and progress of the defence organizations along with their performance. The wide-range of the formulation of the policy for defence, execution and assessment explain the integrity of internal and external contexts of the defence organizations.

\section{CONCEPTUAL FRAMEWORK}

The term conceptual framework refers to the explanation regarding the key facts considered in the research, concept of the research undertaken along with the specific definition. The conceptual framework also describes the area from where the explanations regarding the concept has been derived. To be more specific, this part describes the total origination of the current study. 


\section{REVIEW OF LITERATURE}

Akman (2020) had made a study regarding the defence management and the PESTLE analysis. The department of military has been undergoing a lot of changes and comprises of an environment which is ever evolving in nature. The concept of defence management, along with the field of general management and military science, is looking for opportunities, methods and possibilities for transformation, in the current era of dynamic context and environment. The management, command and to take a lead, needs the knowl3dge about the happenings round the world, awareness about the present scenario of socio-politics, environmental, economic, legal and scientific conditions and also the awareness of surrounding environment of the organization. PESTLE analysis gives an opportunity to the managers of the defence department to provide an answer to all the aforesaid queries. The author of this article had discussed the facts about the PESTLE model and had also attempted to identify a remedy through which the model can be improved with the help of a strategic approach.

Saragih et al. (2016) had done a study whose main aim was to make an analysis of the defence management of Indonesia in the twenty-first century from the point of view of the maritime security of Indonesia. The authors had also determined the willingness of the capabilities defence management to face any form of threats and dangers. The study had made use of a descriptive and qualitative research. documentation and interviews had been performed to collect the data needed for the study. The findings of the research revealed that the Indonesian maritime security had not been developed and organized in a comprehensive and structured way as per the perspective of defence management of the other nations.

Gestão and Brick (2019) had stated that the concept of DL (defence logistics) is a significant but not an explored area of knowledge regarding the production engineering. Hence, the aim of this study was to develop the domain of issues regarding defence logistics. The specific attention had been given to technological, industrial, organizational and more particularly the aspects of strategic management that are implemented in logistics of the defence department. The study also proposed the conceptual framework which identified the objectives of defence logistics, the environmental interfaces and the functional areas. The framework of the study defined the DLB (defence logistics base) to be the system for the creation and sustenance of the capability of the military organization. it also comprises of the growth of the capability of the industry which is associated with the high and medium technologies.

\section{CONCLUSION}

The concept of defence management comprises of a wide range of working procedures like the analysis of the systems and structures, to plan and to program, to model and to simulate, creating alternatives, measurement of performance, improvement of the processes, management of the project, risk assessment and several other techniques and methods which are applicable to varied elements of development and 
implementation of the policy in defence organizations. Defence management proves to be the major tool to support any kind of activities performed for the transformation in the field of defence.

In the historical contexts, the concept of defence management had been evolved as the key area of study and also implementation only in recent times. The concept had been introduces only since the last fifty years, when the western countries familiarized the management of defence to address the problems of allocation of financial as well as human resources, to solve operational or strategic issues in a comprehensive way or to use the tools of business to govern the defence department. One of the ways to achieve excellence in all the departments of the defence sector is to implement the functions of management (to plan, organize, lead and control) the different departments and activities of defence institutions which are capable of increasing the performance of the armed forces.

\section{REFERENCES}

Akman, M. (2020). Defence Management And PESTLE Analysis. Ante Portas - Studianadbezpieczeństwem, 14(1), 93-102. 10.33674/3201910

Gestão, P., \& Brick, E. (2019). A Conceptual Framework For Defence Logistics. Gestão\&Produção, 26.10.1590/0104-530x4062-19

Saragih, Herlina\&amp;barnas, \& Rayanda\&amp;purwanto, P. (2016). Defence Management Concepts Improving Indonesian Maritime Security. Jurnalpertahanan, 2, 257. 10 .33172/Jp.V2i3.104 